\title{
Association study between GSTM1 and GSTT1 genotypes and other possible risk factors in prostate cancer patients in a population from southwest Bahia, Brazil
}

\author{
L.C.F. de Souza $^{1 *}$, T.L.S. Brito ${ }^{1 *}$, A.T. Almeida ${ }^{1}$, Y.P. Muniz ${ }^{1}$, \\ P.B. Nishiyama ${ }^{3}$, C.L. Souza ${ }^{2}$ and L. Tomazi ${ }^{3}$ \\ ${ }^{1}$ Instituto Multidisciplinar em Saúde, Universidade Federal da Bahia, Vitória \\ da Conquista, BA, Brasil \\ ${ }^{2}$ Núcleo de Humanidade e Clínica Ampliada, Instituto Multidisciplinar em \\ Saúde, Universidade Federal da Bahia, Vitória da Conquista, BA, Brasil \\ ${ }^{3}$ Núcleo de Biointegração, Instituto Multidisciplinar em Saúde, \\ Universidade Federal da Bahia, Vitória da Conquista, BA, Brasil \\ * These authors have equally contributed to this study. \\ Corresponding author: T.L.S. Brito \\ E-mail: thaamaralouisy@ hotmail.com \\ Genet. Mol. Res. 18 (3): gmr18296 \\ Received March 07, 2019 \\ Accepted July 11, 2019 \\ Published July 31, 2019 \\ DOI http://dx.doi.org/10.4238/gmr18296
}

\begin{abstract}
Prostate cancer (PCa) is the second most common type of tumor among men over 50 years old and its etiology includes environmental, demographic, and genetic risk factors. We investigated a possible association between GSTMI and GSTT1 polymorphisms, sociodemographic, and clinical factors with $\mathrm{PCa}$ in a population of southwestern Bahia, Brazil. The research used a casecontrol design and was carried out with 268 men aged 50 years or older (134 cases and 134 controls). The mean age was 74 years old ( \pm $7.9)$ in the case group and 55 years old $( \pm 4.3)$ in the control group. Polymorphisms were determined by multiplex PCR, followed by electrophoresis. The genotypic frequencies found were 0.45 for GSTM1 -/- (null), 0.55 for GSTM1 +/- or +/+ (non-null), 0.37 for GSTT1 -/- (null) and 0.62 for GSTT1 +/- or +/+ (non-null). The estimated allele frequencies were: GSTMI - (null allele) 0.60 for the
\end{abstract}


case group and 0.67 for the control group, and GSTT1 - (null allele) 0.49 for the case group and 0.65 for the control group. These polymorphisms were not significantly associated (P-values 0.68 and 0.21 , respectively) with PCa. However, non-white ethnicity (selfreported), sexually transmitted infections, and cigarette consumption were significantly associated with PCa (P-value: $0.03,0.05$ and < 0.01 respectively). Vasectomy exhibited an inverse association ( $\mathrm{P}$ value $<0.01$ ), thus behaving as a protective factor for PCa.

Key words: Polymorphism; GSTM1; GSTT1; Risk factor; Prostate cancer

\section{INTRODUCTION}

It is estimated that in two decades the number of new cases for some type of cancer will increase by $70 \%$ (World Health Organization - WHO, 2016). In Brazil, non-melanoma skin cancer is the most common type, followed, in men, by prostate cancer (PCa) and, in women, by breast cancer (National Cancer Institute - INCA, 2018). The highest incidence of PCa occurs in South and Southeast regions of the country. Each year, the number of new cases increases throughout the country, which is attributed to extended life expectancy and improvement in diagnosis techniques (Facina, 2016). In Brazil, in 2013, approximately 14,000 deaths were ascribed to this type of cancer, and in 2018, it is estimated that there will be reported 68,220 new cases of PCa (INCA, 2018).

According to American Society Cancer (2018), projections for PCa in the United States, in 2018, there were about 164,690 new cases and 29,430 deaths owing to PCa. The incidence rates of $\mathrm{PCa}$ vary among the countries, with highest rates in Australia, New Zealand, North America, and Western Europe while the lowest numbers are in South Central Asian populations (International Agency for Research on Cancer - IARC, 2016).

The emergence of cancer may be related to individual ability to metabolize carcinogenic compounds in routes involving enzymes for xenobiotics elimination (Mannervik et al., 1992). Toxic substances go through different stages of cell detoxification. Among the mechanisms involved, there are enzymes belonging to Glutathione STransferases (GSTs) family, which are divided into two large groups, one located at the microsomal membrane and the other present in cytosol. All cytosolic GSTs present genetic polymorphisms in human populations and are subdivided into six classes. Among them, the most studied classes are the $M u$-class GSTs, whose proteins are encoded by GSTM1 gene, and the Theta class GSTs, encoded by GSTT1 gene (Silva et al., 2015). GSTM1 gene, chromosomal location 1p13.3, has three described alleles: two characterized as non-null with functional activity and one null GSTM1 genotype, described as an allelic version of gene deletion (Wei et al., 2012; Sá et al., 2014). GSTT1 gene (22q11.23) has two non-null and functional alleles: non-null and functional GSTT1 and null, non-functional GSTT1. The investigation of GSTM1 and GSTT1 gene polymorphisms is justified by the potential of these molecular factors to be related to loss of cellular mechanisms for protection against cancer (Yang et al., 2013; Berta et al., 2014; Sá et al., 2014).

The objective of our study was to investigate possible associations between GSTM1 and GSTT1 gene polymorphisms, sociodemographic, and clinical factors with $\mathrm{PCa}$ in a population of the state of Bahia, Brazil. 


\section{MATERIAL AND METHODS}

\section{Study sample}

We used a case-control design and included 268 male individuals, aged 50 years or older, attended in Vitória da Conquista, Bahia. Among these, 134 belonged to the case group (with diagnosis of PCa by anatomopathological examination) and the other 134 to the control group (healthy individuals, without cancer). Case group individuals were invited to participate in the study from July 2015 to January 2016, at the High Complexity Unit in Oncology (Unidade de Alta Complexidade em Oncologia - UNACON) and the control group members took part in the research from December 2015 to April 2016 at the Southwest Hemotherapy Service (Serviço de Hemoterapia do Sudoeste - SHS). All participants signed an Informed Consent form. The research project was approved by the Research Ethics Committee of the Multidisciplinary Institute of Health of the Federal University of Bahia (IMS-UFBA), under the protocol number 30879614.3.0000.5556, approval opinion 1.325.852.

\section{Data collect}

Data and sample collection included: (i) a questionnaire (in which patient information was included) and (ii) a peripheral blood sample. All data and samples were collected at the institution where the research participants were attended. The assembled information was distributed in the following categories: (i) demographic, (ii) life habits, and (iii) health conditions.

Samples of $3 \mathrm{~mL}$ from peripheral blood were collected from each patient in EDTA tubes. They were transported in refrigerated boxes to the Laboratory of Cellular and Molecular Biology of the IMS-UFBA to perform genotyping.

\section{Genetic analysis}

Genomic DNA was isolated using the Brasílica kit (LGC Biotecnologia, SP, Brazil), following the manufacturer's protocol. The samples were amplified by multiplex PCR, using Taq DNAPolimerase (Invitrogen ${ }^{\mathrm{TM}}$, SP, Brazil), thermal cycler MyGenie96 thermal block (Bionner, Korea), and three pairs of primers. The primers used were: (i) one for GSTM1 (sense 5' GAA CTC CCT CAA AAG CTA AAG C 3' e antisense 5' GTT GGG CTC AAA TAT ACG GTG G 3'), (ii) another for GSTT1 (sense 5' TTC CTT ACT GGT CCT CAC ATC TC 3' e antisense 5' TCA CCG GAT CAT GGC CAG CA 3') described by Kumar et al. (2011), and (iii) the third for beta-globin (sense 5' CAA CTT CAT CCA CGT TCA CC 3' e antisense 5' GAA GAG CCA AGG ACA GGT AC 3') (Sá et al., 2014). $\beta$-globin gene was used as a positive control of the reaction. The negative control (containing all reagents except DNA) was also applied. Reaction conditions used for a final volume of $25 \mu \mathrm{L}$ were: $1 \mathrm{x}$ buffer; $3.5 \mathrm{mM}$ of $\mathrm{MgCl}_{2} ; 0.2 \mathrm{mM}$ of dNTPs; $0.5 \mu \mathrm{M}$ of each primer; 0.03 units $/ \mu \mathrm{L}$ de Taq DNAPolimerase and approximately 42 ng DNA (per reaction). Thermocycling conditions were: (i) initial denaturation at $94^{\circ} \mathrm{C}$ for $5 \mathrm{~min}$; (ii) 30 cycles of: $94^{\circ} \mathrm{C}$ for $1 \mathrm{~min}, 62^{\circ} \mathrm{C}$ for $1 \mathrm{~min}, 72^{\circ} \mathrm{C}$ for $1 \mathrm{~min}$; and (iii) final extension at $72^{\circ} \mathrm{C}$ for $7 \mathrm{~min}$. Conditions adapted from Kumar et al. (2011). 
PCR products were applied (volume of $15 \mu \mathrm{L}$ of the PCR in each channel) in $0.5 \%$ agarose gel, stained with ethidium bromide and visualized under ultraviolet light. The fragments obtained were: (i) $215 \mathrm{bp}$, which identifies GSTM1 non-null genotype (in homozygosis or heterozygosity); (ii) 459bp, which identifies GSTT1 non-null genotype (in homozygous or heterozygosis) and (iii) $273 \mathrm{bp}$, corresponding the amplification of the positive reaction control ( $\beta$-globin gene). GSTM1 null genotype was identified as the absence of the 215bp fragment and the GSTT1 genotype was null as the absence of the $459 \mathrm{bp}$ fragment. Fragment sizes were estimated comparing with molecular weight marker (Universal marker, 100pb-1Kb DNA, LGC Biotechnology, SP, Brazil). Molecular techniques employed by the present work do not distinguish between non-null homozygous genotypes and heterozygous non-null genotypes.

\section{Statistical analysis}

The following potential explanatory variables for PCa occurrence were evaluated in this study: demographic, life habits, health status, and GSTM1 and GSTT1 genes polymorphisms. Descriptive analysis was performed through (i) relative frequency for categorical variables and (ii) measures of central tendency (as mean and median) for continuous variables. The explanatory variable of the univariate analysis was the conclusive diagnosis of PCa by biopsy. The association between response and explanatory variables was estimated by odds ratio (OR), with $95 \%$ confidence intervals (CI). The chi-square test was used with the Yates correction or Fisher's exact test and multivariate analysis to measure the differences, considered significant at $\mathrm{P} \leq 0.05$. All analyzes were performed using EPI INFO software, version 7.1.5. The Hardy-Weinberg principle was used to calculate the allelic and genotype frequencies specific to non-null homozygous genotypes $(+/+)$ and heterozygotes $(+/-)$. The frequencies of homozygous null genotypes (-/-) were determined in the present work by genotyping.

\section{RESULTS}

The mean age of the research's participants was 74 years old \pm 7.9 for the case group, and 55 years old \pm 4.3 for the control group. In the case group, the most frequent Gleason scores were 7 (46.3\%) and 6 (28.4\%)

For individuals' genotypes, different genotypic combinations were obtained, they were: (1) GSTMI null (-/-) and GSTT1 non-null (+/+ or +/-) genotypes, (2) GSTM1 non-null (+/+ or +/-) and GSTT1 non-null (+/+ or +/-) genotypes, (3) GSTM1 non-null (+/+ or +/-) and GSTT1 null (-/-) genotypes, and (4) GSTMI null (-/-) and GSTT1 null (-/-) genotypes.

In the analysis of the genotypes seen in Table 1, the GSTM1 polymorphism, null genotype (-/-) was present in $35.8 \%$ of the individuals in case group and $44.8 \%$ of the control group representatives. For GSTT1 polymorphism, the null genotype (-/-) was detected in $23.9 \%$ of the case group participants and in $42.5 \%$ of the control group. When we considered double null genotypes (the same individual with deletion for both investigated genes), this event occurred in $8.2 \%$ of the case group population and $20.2 \%$ of the control group participants. Regarding the presence of $\mathrm{PCa}$ cases in the family (considering first - and second - degree kinship - parents, siblings, children, grandparents, uncles, and cousins), $35.8 \%$ of the case group reported occurrence, in contrast to $24.6 \%$ of the 
control group (Table 2). The estimated allele frequencies were: GSTMI - (null allele) 0.60 for the case group and 0.67 for the control group, and GSTT1 - (null allele) 0.49 for the case group and 0.65 for the control group (data not shown in table). The frequencies of the non-null alleles are the complementary frequencies.

Table 1. GSTM1 and GSTT1 gene polymorphisms associated with prostate cancer in case and control groups.

\begin{tabular}{|c|c|c|c|c|}
\hline Variables & $\begin{array}{l}\text { Patients } \\
\text { n }(\%)\end{array}$ & $\begin{array}{l}\text { Controls } \\
\text { n }(\%)\end{array}$ & $\begin{array}{l}\text { Odds Ratio } \\
(95 \% \text { CI })\end{array}$ & P-value* \\
\hline \multicolumn{5}{|l|}{ GSTMI } \\
\hline Null & $48(35.8)$ & $60(44.8)$ & $1.17(0.68-2.01)$ & \\
\hline Non-null & $86(64.2)$ & $74(55.2)$ & 1 & 0.68 \\
\hline \multicolumn{5}{|l|}{ GSTT1 } \\
\hline Null & $32(23.9)$ & $57(42.5)$ & $0.64(0.35-1.19)$ & \\
\hline Non-null & $102(76.1)$ & $77(57.5)$ & 1 & 0.21 \\
\hline
\end{tabular}

Sample: 268 men (134 cases, 134 controls), age $\geq 50$ years old, attended from 2015 to 2016 by the Health System of Vitória da Conquista, Bahia, Brazil. *Statistical significance $(\mathrm{P}<0.05)$. Genotype frequencies of homozygous null genotypes were obtained by genotyping (through experiments). Frequencies of non-null genotypes (homozygous and heterozygous) were achieved using the expected allele frequencies attained by the Hardy-Weinberg equation $(\mathrm{p} 2+2 \mathrm{pq}+$ $\mathrm{q} 2=1)$.

Table 2. Demographic and clinical aspects related to the prostate cancer for case and control groups.

\begin{tabular}{|c|c|c|c|c|}
\hline Variables* & $\begin{array}{l}\text { Patients } \\
\text { n }(\%)\end{array}$ & $\begin{array}{l}\text { Controls } \\
\text { n }(\%)\end{array}$ & $\begin{array}{l}\text { Odds Ratio } \\
(95 \% \text { CI })\end{array}$ & $P$-value** \\
\hline \multicolumn{5}{|l|}{ Ethnicity $^{1}$} \\
\hline White & $20(15.0)$ & $37(27.6)$ & 1 & \\
\hline Non-white & $113(85.0)$ & $97(72.4)$ & $2.16(1.17-3.96)$ & 0.016 \\
\hline \multicolumn{5}{|c|}{ Alcohol consumption ${ }^{2}$} \\
\hline Yes & $118(88.1)$ & $117(87.3)$ & 1 & \\
\hline No & $16(11.9)$ & $17(12.7)$ & $1.07(0.52-2.22)$ & 1 \\
\hline \multicolumn{5}{|c|}{ Cigarette consumption $^{3}$} \\
\hline Yes & $103(77.4)$ & $77(58.8)$ & $2.41(1.41-4.11)$ & \\
\hline No & $30(22.6)$ & $54(41.2)$ & 1 & $<0.002$ \\
\hline \multicolumn{5}{|l|}{ Obesity ${ }^{4}$} \\
\hline Yes & 18 (13.4) & $23(17.2)$ & $0.74(0.38-1.46)$ & \\
\hline No & $116(86.6)$ & $111(82.8)$ & 1 & 0.498 \\
\hline \multicolumn{5}{|l|}{ STIs $^{5}$} \\
\hline Yes & $29(21.8)$ & $14(10.5)$ & $2.37(1.19-4.73)$ & \\
\hline No & $104(78.2)$ & $119(89.5)$ & 1 & 0.019 \\
\hline \multicolumn{5}{|l|}{ Vasectomy } \\
\hline Yes & $2(1.5)$ & $17(12.7)$ & $0.11(0.02-0.47)$ & $<0.001$ \\
\hline No & $130(98.5)$ & $117(87.3)$ & 1 & \\
\hline \multicolumn{5}{|c|}{ Cases of PCa in the family ${ }^{6}$} \\
\hline Yes & $48(35.8)$ & $33(24.6)$ & 1 & \\
\hline No & $86(64.2)$ & $101(75.4)$ & $1.71(1.0-2.90)$ & 0.06 \\
\hline
\end{tabular}

Sample: 268 men (134 cases, 134 controls), age $\geq 50$ years old, attended from 2015 to 2016 by the Health System of Vitória da Conquista, Bahia, Brazil. * The maximum number of data lost for each variable was less than 6. ** Univariate analysis (statistical significance P-value < 0.05). Most of the variables described here were self-reported (exceptions are mentioned) in the data collection instrument (questionnaire) by a trained team. Superscript numbers: 1 - Self-reported ethnicity. 2 - Alcohol consumption in the past or in the current days. 3 - Cigarette consumption in the past. 4 - Obesity previously notified to the individual by a healthcare professional. 5 - Presence of Sexually Transmitted Infections (STIs), previously informed by medical report. 6 - First- and second-degree parents (parents, siblings, children, grandparents, uncles, and cousins). 
The distribution of the investigated variables (demographic, life habits, health conditions) and the list of this disease data is shown in Table 2 (univariate analysis). Concerned to the variables described, the presence of PCa cases in the family was close to the degree of significance (P-value 0.06; OR 1.71), but it did not compose the final model, which presents non-white ethnicity (P-value 0.016, OR 2.16), cigarette consumption ( $\mathrm{P}$ value < 0.002, OR 2.41), STIs (P-value 0.019; OR 2.37), and vasectomy (P-value < 0.001; OR 0.11). These variables were independently associated with $\mathrm{PCa}$ in multivariate analysis (Table 3). Vasectomy surgery was presented as a protective factor for the occurrence of PCa.

Table 3. Multivariate analysis of the variables associated with prostate cancer in Vitória da Conquista, Bahia, Brazil.

\begin{tabular}{llr}
\hline Variables* $^{*}$ & $\begin{array}{l}\text { Odds Ratio } \\
\text { (95\% CI) }\end{array}$ & P-value** \\
\hline Non-white Ethnicity (Yes/No) $^{1}$ & $2.06(1.09-3.90)$ & 0.03 \\
Smoking Habit (Yes/No) $^{2}$ & $2.16(1.23-3.77)$ & $<0.01$ \\
STIs (Yes/No) $^{3}$ & $2.07(1.0-4.28)$ & 0.05 \\
Vasectomy (Yes/No) $^{*}$ & $0.12(0.03-0.05)$ & $<0.01$ \\
\hline Sample
\end{tabular}

Sample: 268 men (134 cases, 134 controls), age $\geq 50$ years old, attended from 2015 to 2016 by the Health System of Vitória da Conquista, Bahia, Brazil. *The maximum number of data lost for each variable was less than 6 . **Statistical significance $(\mathrm{P}<0.05)$. Log-likelihood model fit test $=329.578$. Most of the variables described here were self-reported (exceptions are mentioned) in the data collection instrument (questionnaire) by a trained team. Superscript numbers: 1 Self-reported ethnicity. 2 - Cigarette consumption in the past. 3 - Presence of Sexually Transmitted Infections (STIs), previously informed by medical report.

\section{DISCUSSION}

In this study, mean age was different between control and case groups (74 years old for the cases vs. 55 years old for controls). This difference was statistically significant $(\mathrm{P}<$ 0.01). This data is explained by the individuals' profile attended at the sample collection sites. Control representatives were blood donors and the case ones were individuals being treated for PCa. According to INCA (2018), 75\% of PCa cases occur after 65 years old. These data corroborate to the difference in mean age found between the groups in the present work. Agalliu et al. (2006) have also assessed the possible association of GSTMI and GSTT1 with $\mathrm{PCa}$, using case and control groups and encountered age differences as well, where the most frequent age group for control group was 55 - 59 years old and for the cases 60 - 64 years old. Due to this mean age disparity, it was not possible to analyze the element age as a risk factor for PCa.

Perera (1996) has reported that cancer can occur in consequence of accumulation of mutations. Therefore, it is expected that an individual at a later age will have a greater number of accumulated mutations. The results of the present study demonstrate a higher frequency (not statistically significant) of GSTM1 and GSTT1 null genotypes in the control group, which indicates that there is no relation between age (higher in the case group) and the mutations analyzed here (present in the null genotypes). Hence, there is no evidence to believe that the mean age difference between the groups influence our study of the association of GST genotypes with PCa. 
The polymorphisms of the investigated genes GSTM1 and GSTT1 revealed no association with PCa in the studied population. Recent studies of Brazilian populations have analyzed the relation between GSTMI and GSTT1 polymorphism with PCa and corroborate with this behavior. In a study conducted on residents from the south of the country (Londrina, Paraná), no association was established (Rodrigues et al., 2011). Sá et al. (2014) also obtained non-association findings in a sample from southeastern Brazil (Rio de Janeiro, RJ). The absence of association between GST gene polymorphisms and PCa was likewise observed in a population of the city of Rawalpindi, Pakistan (Malik et al., 2015).

Researchers have presented that when an association between GSTs and PCa is detected, most occur with only one of the genes. Meta-analysis studies indicate that only GSTM1 was associated with PCa (Zengnan et al., 2009; Cao et al., 2015). In a population from north India, both genes were correlated with PCa, although it was verified a higher prevalence of GSTT1 null genotype (Mittal et al., 2004). In regions of Tunisia and Turkey, GSTT1 gene was seen to be associated with PCa (Souiden et al., 2010; Berber et al., 2013). The presence of GSTT1 gene has also been shown to be associated with PCa in a Caribbean population, thus requiring more studies for better understanding (Mallick et al., 2007). The possible connection with GST polymorphisms has not been reported exclusively with PCa, but also with other types of tumor such as colorectal, lung, and bladder (Economopoulos and Sergentanis, 2010; Tamaki et al., 2011; Matic et al., 2013).

Regarding heredity, the findings in this study did not have a statistical association with family history of PCa (first- and second-degree kinship), although P-value of 0.06 demonstrates a probable relation if the level of significance was extended to $90 \%$. Differently, Emeville et al. (2014) has detected a relevant association with a really significant P-value, equivalent to 0.001, in individuals of a Caribbean population.

Non-white ethnicity (self-reported) revealed a significant association with PCa (Pvalue 0.03 ). The group that had the highest frequency of non-whites representatives was the case group. The results also indicate that non-white individuals have 2.06 times the chance of developing the disease. The prevalence of PCa varies with geographic location and ethnic composition of the evaluated populations (Berber et al., 2014). Some works have related ethnicity to PCa in certain populations (Kwon et al., 2011; Berber et al., 2013; Emeville et al., 2014; Cao et al., 2015). Jamaicans and Caribbeans of African descent have the highest incidences of PCa in the world; which may be attributed in part to heredity (Facina, 2016). In most researches, black men were more likely to develop PCa compared to non-black men (Kheirandish and Chinegwundoh, 2011).

Cigarette consumption was statistically related with $\mathrm{PCa}$ in the analyzed sample (Pvalue $<0.01$ ), with a 2.16-fold chance of developing the disease for individuals who had smoked. The findings acquired here corroborate to the researchers conducted by Huncharek et al. (2010), who have reported the same linkage. The possible explanation for this association would be that exposure to toxic substances in smoke, such as polycyclic aromatic hydrocarbons, increases the risk of mutations (Leitzmann and Rohrmann, 2012).

Another risk factor associated with PCa was the history of STIs (P-value 0.05). Individuals who reported STIs present 2.07 times the chances of having this type of cancer. Studies by Cheng et al. (2010) found an association between STD and PCa, while Caini et al. (2014) research have pointed to gonorrhea as the STI most related to the tumor. Although, the mechanisms of relationship between emergence of PCa and STDs still require further research to be elucidated. Regarding vasectomy variable, the results revealed a 
protective association with $\mathrm{PCa}(\mathrm{P}$-value $<0.001)$. This relation was not found by many studies, being absent in Ganesh et al. (2011) and Tyagi et al. (2010)'s researches. It is possible that, concerned to other studied variables, vasectomy has a frequency more influenced by the stochasticity of a small sample.

Considering populations from northeastern Brazil, research on molecular epidemiology involving GSTs and cancer genes was performed by Arruda et al. (1998), Gattás et al. (2004), Silva et al. (2014), and Santos (2017).

Arruda et al. (1998) analyzed the possible relationship of different ethnic groups (including blacks) and the prevalence of GSTM1 and GSTT1 with environmental carcinogenesis in populations from different Brazilian regions, including Salvador, Bahia. In this study, the authors have verified the prevalence of null genotype for GSTM1 among Caucasians (55\%), followed by Brazilian blacks (33\%), and homogenous distribution of GSTT1 among Caucasians and African descendants. Gattás et al. (2004) while studying different ethnicities (identified by the interviewer) from São Paulo and Salvador, Bahia, have not identified an association between GSTM1 and GSTT1 with cancer risk (cancer in general, not specifically PCa). However, these authors have detected a significantly higher frequency of GSTMI null genotype among whites than non-whites (mulattoes and blacks) in the São Paulo group.

Silva et al. (2014) evaluated the association between GSTMI and GSTT1 genes with upper aerodigestive tract cancer in Ilhéus and Itabuna (State of Bahia). They encountered frequencies of null GSTM1 greater in the case group than in the control, and null GSTT1 among controls than in the cases; however, no statistical significance was found. Santos (2017) conducted a research on the association between GSTM1 and GSTT1 gene polymorphisms with the susceptibility and prognosis of PCa in Piauí, in Northeast Brazil. Both null GSTM1 and null GSTT1 demonstrated to be statistically associated with the presence of PCa, being the GSTM1 null genotype as protective and null GSTT1 as a risk factor; although, when both genotypes were analyzed in association, there was no statistical significance.

This is the first study on molecular epidemiology and risk factors for PCa in the southwest region of Bahia. The different association of variables among the populations can be explained due to their particular characteristics. Because of this variation, the study of gene polymorphisms and their relation with cancer should be performed in specific populations. Moreover, our study confirms putative factors for $\mathrm{PCa}$ that other publications have revealed, though we recommend additional studies to confirm these findings, due to sampling limitations in our investigation.

\section{ACKNOWLEDGMENTS}

We would like to thank the High Complexity Unit in Oncolocy (Unidade de Alta Complexidade em Oncologia - UNACON), especially Ana Cecília L. Ferraz; the laboratory technician of UFBA, Janeide M. Oliveira; the Southwest Hemotherapy Service - (Serviço de Hemoterapia do Sudoeste - SHS), particularly Flávio Marinho Narici; the undergraduate students in Biotechnology from UFBA, Eduarda Sales de Melo, Gustavo M. Oliveira, and Ítalo P. Santana; and PIBIC (Institutional Program for Scientific Initiation Fellowships, granted by FAPESB and UFBA) and Permanecer Program. 


\title{
CONFLICTS OF INTEREST
}

\author{
The authors declare no conflict of interest.
}

\section{REFERENCES}

American Society Cancer (ACS), https://www.cancer.org/cancer/prostate-cancer/about.html Accessed July 8, 2018.

Agalliu I, Langeberg WJ, Lampe JW, Salinas CA, et al. (2006). Glutathione S-transferase M1, T1, and P1 polymorphisms and prostate cancer risk in middle-aged men. Prostate. 66(2): 146-156.

Arruda $\quad$ VR, Grignoli CE, Gonçalves MS, Soares MC et al. Prevalence of homozygosity for the deleted alleles of glutathione Stransferase mu (GSTMl) and theta $(G S T T l)$ amon g distinct ethnic groutx from Brazil: relevance to enviromental carcinogenesis? Clin. Gen. 54: 210-214.

Berber U, Yilmaz I, Yilmaz O, Haholu A, et al. (2013). Influence of GSTM1, GSTP1, and GSTT1 gene polymorphisms on prostate cancer risk in Turkish population. UHOD 23: 242-249.

Berber U, Haholu A, Yilmaz O, Yilmaz I, et al. (2014). Lack of Association between Glutathione S-Transferase -M1 and -T1 Gene Polymorphisms with Clinicopathological Parameters in Prostate Cancer. Dis. Mol. Med. 2: 1-6.

Caini S, Gandini S, Dudas M, Bremer V, et al. (2014). Sexually transmitted infections and prostate cancer risk: a systematic review and meta-analysis. Cancer Epidemiol. 38: 329-338.

Cheng I, Witte JS, Jacobsen SJ, Haque R, et al. (2010). Prostatitis, sexually transmitted diseases, and prostate cancer: the California Men's Health Study. PLoS One. 5: e8736.

Economopoulos KP $\beta$-globin Sergentanis TN (2010). GSTM1, GSTT1, GSTP1, GSTA1 and colorectal cancer risk: a comprehensive meta-analysis. Eur. J. Cancer. 46: 1617-1631.

Emeville E, Broquère C, Brureau L, Ferdinand S, et al. (2014). Copy number variation of GSTT1 and GSTM1 and the risk of prostate cancer in a Caribbean population of African descent. PloS One. 9: e107275.

Facina T (2016). Estimativa 2016 Incidência de Cáncer no Brasil. Instituto Nacional de Cáncer José Alencar Gomes da Silva e Ministério da Saúde, Rio de Janeiro. http://santacasadermatoazulay.com.br/wpcontent/uploads/2017/06/estimativa-2016-v11.pdf. Accessed June 4, 2019.

Ganesh B, Saoba SL, Sarade MN and Pinjari SV (2011). Risk factors for prostate cancer: An hospital-based case-control study from Mumbai, India. Indian J. Urol. 27: 345-350.

Gattás, GJF, Kato M, Soares-Vieira JÁ, Siraque MS, et al. (2004). Ethnicity and glutathione S-transferase (GSTM1 /GSTT1) polymorphisms in a Brazilian population. Braz. J. Medl. Biol. Res. 37: 451-458.

Huncharek M, Haddock KS, Reid R and Kupelnick B (2010). Smoking as a risk factor for prostate cancer: a metaanalysis of 24 prospective cohort studies. Am. J. Public. Health. 100: 693-701.

Instituto Nacional do Câncer (INCA), http://www.inca.gov.br Accessed July 5, 2018.

International Agency for Research on Cancer (IARC). World Health Organization, http://globocan.iarc.fr/old/FactSheets/cancers/prostate-new.asp, Accessed April 10, 2018.

Kheirandish $\mathrm{P}$ and Chinegwundoh $\mathrm{F}$ (2011). Ethnic differences in prostate cancer. Br. J. Cancer. 105: 481-485.

Kumar V, Yadav CS, Datta SK, Singh S, et al. (2011). Association of GSTM1 and GSTT1 polymorphism with lipid peroxidation in benign prostate hyperplasia and prostate cancer: a pilot study. Dis. Markers. 30(4): 163-169.

Kwon DD, Lee JW, Han DY, Seo IY, et al. (2011). Relationship between the glutathione-S-transferase P1, M1, and T1 genotypes and prostate cancer risk in Korean subjects. Korean J. Urol. 52: 247-252.

Leitzmann MF and Rohrmann S (2012). Risk factors for the onset of prostatic cancer: age, location, and behavioral correlates. Clin. Epidemiol. 4: 1-11.

Malik SS, Masood N and Yasmin A (2015). Prostate cancer and glutathione S-transferase deletions. EXCLI J. 14: 10491054.

Mallick S, Romana M, Blanchet P, et al. (2007). GSTM1 and GSTT1 polymorphisms and the risk of prostate cancer in a Caribbean population of African descent. Urology. 69: 1165-69.

Mannervik B, Awasthi YC, Board PG, et al. (1992). Nomenclature for human glutathione transferases. Biochem. J. 282: 305-6.

Matic M, Pekmezovic T, Djukic T, Mimic-Oka J, et al. (2013). GSTA1, GSTM1, GSTP1, and GSTT1 polymorphisms and susceptibility to smoking-related bladder cancer: a case-control study. Urol. Oncol. 31: 1184-1192.

Mittal RD, Srivastava DSL, Mandhani A, Kumar A, et al. (2004). Polymorphism of GSTM1 and GSTT1 genes in prostate cancer: A study from North India. Indian J. Cancer. 41: 115-119.

Organização Mundial da Saúde (OMS), http://www.who.int/mediacentre/factsheets/fs297/en/, Accessed April 10, 2019.

Perera FP (1996). Molecular epidemiology: insights into cancer susceptibility, risk assessment, and prevention. J. Natl. Cancer Inst. 88: 496-509.

Rodrigues IS, Kuasne H, Losi-Guembarovski R, Fuganti PE, et al. (2011). Evaluation of the influence of polymorphic variants $C Y P 1 A 1 * 2 \mathrm{~B}, C Y P 1 B 1 * 2, C Y P 3 A 4 * 1 \mathrm{~B}, G S T M 1 * 0$, and $G S T T 1 * 0$ in prostate cancer. Urol. Oncol. 29: 654-663.

Genetics and Molecular Research 18 (3): gmr18296

OFUNPEC-RP www.funpecrp.com.br 
Sá RAD, Moreira ADS, Cabello PH, Ornellas AA, et al. (2014). Human glutathione S-transferase polymorphisms associated with prostate cancer in the Brazilian population. Int. Braz. J. Urol. 40: 463-473.

Santos BB (2017). Associação dos polimorfismos GSTM1 nulo e MTHFR C677T com susceptibilidade e prognóstico do câncer de próstata de alto risco em pacientes no estado do Piauí. Masters Thesis. Programa de Pós-graduação em Biotecnologia (PPGBiotec) da Universidade Federal do Piauí (UFPI), Campus Ministro Reis Velloso.

Silva CND, Silva DND, Moraes KL, Cordeiro JABL, et al. (2015). GSTM1 and GSTT1 genes null polymorphisms in kidney cancer susceptibility: evidence based on a meta-analysis. J. Bras. Nefrol. 37(2): 248-254.

Silva TM, Marques CR, Marques Filho MF, Marques AB, et al. (2014). Association of the GSTT1 polymorphism in upper aerodigestive tract cancer with tobacco smoking. Genet. Mol. Res. 13: 528-537.

Souiden Y, Mahdouani M, Chaieb K, Elkamel R, et al. (2010). Polymorphisms of glutathione-S-transferase M1 and T1 and prostate cancer risk in a Tunisian population. Cancer Epidemiol. 34: 598-603.

Tamaki Y, Arai T, Sugimura H, Sasaki T, et al. (2011). Association between Cancer Risk and Drug-metabolizing Enzyme Gene (CYP2A6, CYP2A13, CYP4B1, SULT1A1, GSTM1 and GSTT1) Polymorphisms in Cases of Lung Cancer in Japan. Drug Metab. Pharmacokinet. 26: 516-522.

Tyagi B, Manoharan N and Raina V (2010). A case control study on prostate cancer in Delhi. Asian Pac. J. Cancer Prev. 11: 397-401.

Wei B, Xu Z, Zhou Y, Ruan J, et al. (2012). Association of GSTM1 null allele with prostate cancer risk: evidence from 36 case-control studies. PloS One. 7: e46982.

Yang Q, Du J and Yao X (2013). Significant association of Glutathione S-transferase T1 null genotype with prostate cancer risk: a meta-analysis of 26,393 subjects. PloS One. 8: e53700.

Zengnan M, Yong G, Yunfei C, Feng G, et al. (2009). An updating meta-analysis of the GSTM1, GSTT1, and GSTPI polymorphisms and prostate cancer a HuGE review. Prostate. 69: 662-88 